\title{
Adsorption of anionic azo dye from aqueous solution using Strychnos potatorum Linn seeds: isotherm and kinetic studies
}

\author{
M. Kirupa Sankar · K. Muthu Kumar • \\ B. V. Ranganathan
}

Received: 27 February 2014/Revised: 25 June 2014/ Accepted: 11 August 2014/Published online: 28 August 2014

(C) Islamic Azad University (IAU) 2014

\begin{abstract}
Dyes from several industry effluents are major concern of environmental pollution. In this study, the efficiency of a cost-effective natural adsorbent Strychnos potatorum Linn (Fam: Loganiaceae) seeds on removing reactive orange-M2R dye from aqueous solution was investigated using batch adsorption isotherms at $30 \pm 1{ }^{\circ} \mathrm{C}$ and $120 \mathrm{rpm}$. The efficacy of the adsorbent system was also studied at various parameters viz. contact time, $\mathrm{pH}$, adsorbent dosage and initial dye concentration. Maximum adsorption $\left(q_{\mathrm{e}}=9 \mathrm{mg} / \mathrm{g}\right)$ was observed at $\mathrm{pH} 2.0$, equilibrium time $6 \mathrm{~h}$, initial dye concentration of $100 \mathrm{mg} / \mathrm{L}$ and adsorbent dosage of $0.2 \mathrm{~g} / 100 \mathrm{~mL}$. The unit adsorption of dye, $q_{\mathrm{e}}(\mathrm{mg} / \mathrm{g})$ increased with increase in contact time and initial dye concentration, while it decreased with increase in adsorbent dosage. The adsorption kinetic studies revealed that it follows pseudo-second-order reaction model. Equilibrium adsorption data followed both Langmuir and Freundlich isotherms with good agreement. These investigations suggest that Strychnos potatorum Linn seeds (SPS) could be used as a low-cost adsorbent in treating textile effluents for dye removal applications. The adsorbent (SPS) was also characterized using Fourier transform infrared spectroscopy, powder X-ray diffraction, and scanning electron microscopic technique.
\end{abstract}

Keywords Strychnos potatorum Linn seeds - Adsorption · Environment · Dye removal · Reactive orange-M2R

M. Kirupa Sankar $(\bowtie) \cdot$ K. Muthu Kumar · B. V. Ranganathan Department of Biotechnology, Bannari Amman Institute of Technology, Sathyamangalam, Erode 638401, Tamilnadu, India e-mail: krpasnkr@gmail.com

\section{Introduction}

Many researchers have tried to provide methods for pollution prevention by providing adequate treatment of the effluents from industrial and residential sources (Sid Kalal et al. 2012). One of the major problems of water bodies (rivers and lakes) is the release of waste water from several dyeing industries (Khan et al. 2004). In India, many industries viz, textile, leather, printing, food etc., use dye as a coloring agent. Around 10,000 commercial dyes are available in the market and among these, $60-70 \%$ are azo dyes. In general, azo dyes are categorized based on its chemical structure (monoazo, diazo, triazo and tetraazo dyes) and other by its application (acidic, basic, direct, reactive, pigments and disperse). In textile industry, for dyeing purpose, 30-60 $\mathrm{L}$ of water is consumed per $\mathrm{kg}$ of cloth dyed. It is reported that after processing, 10-15\% of the dyes present in the effluent contaminates local water bodies (Sivaraj et al. 2000). The effluent imparts color and reduces the sunlight penetration and thereby retards the growth of flora and fauna by affecting photosynthesis. The effluent also contains various carcinogens and mutagens which are detrimental to the mankind (Gregory et al. 1991). Ozacar and Sengil (2003) reported that several harmful chemicals in the effluent cause chelation of metal ions. This in turn, depletes the dissolved $\mathrm{O}_{2}$ concentration which adversely affects fish and other aquatic organisms by producing micro-toxicity.

Most of the dyes used in dying section are stable against biological and photo-degradation. Presently, several chemical and physical treatment methods are available to treat the dye industry effluents. But, these methods are not economical and effective against wide range of dyes. Several works have been reported on conventional and non-conventional adsorbents for the dye removal from 
aqueous solution (Pollard et al. 1992; Namasivayam et al. 2001; Ramakrishna and Viraraghavan 1997). The liquid phase adsorption was found to be highly efficient for the removal of color (Garg et al. 2004a, b). In addition, regeneration of adsorbent also should be taken into account to make the method an economically viable one.

In this present study, the use of Strychnos potatorum Linn Seeds (SPS) as an adsorbent for the removal of reactive orange-M2R (RO-M2R), a monoazo dye was explored. Kirtikar and Basu (1933) reported that Strychnos potatorum Linn (deciduous tree) is widely available in central and southern parts of India, Sri lanka and Burma. The seeds of this tree are known for purifying mud water and thus have its common name as "clearing nut tree". Besides, there are several reports available on medicinal importance of the fruits of this tree (Kirtikar and Basu 2000). The aim of the present work is to find out the ability of SPS as a low-cost, naturally available adsorbent for the removal of RO-M2R dye under optimized conditions.

This research work was carried out at Department of Biotechnology, Bannari Amman Institute of Technology, Tamilnadu, India during May to October 2013.

\section{Materials and methods}

\section{Adsorbent and adsorbate}

Strychnos potatorum Linn seeds was purchased from the Parrys market, Chennai, India. The SPS was dried in hot air oven at $70{ }^{\circ} \mathrm{C}$ for $48 \mathrm{~h}$ and powdered using a grinder. The powdered adsorbent was sieved through a $250 \mu \mathrm{m}$ diameter mesh. RO-M2R was procured from local textile dyeing unit, Tirupur, Tamil Nadu, India. Other chemicals used in the experiment were of highest purity and of analytical grade. The absorbance of samples was measured using UV-Vis Spectrophotometer (Perkin Elmer, Lambda-35).

\section{Batch adsorption studies}

The batch dye adsorption studies were conducted by agitating $100 \mathrm{~mL}$ volume of reactive dye solution of known concentration $(5-200 \mathrm{mg} / \mathrm{L})$ with $0.2 \mathrm{~g}$ of SPS in $250 \mathrm{~mL}$ conical flask. Dye solution was prepared by adding distilled water in order to minimize possible interferences caused by tap water. Agitation was carried out in a mechanical shaker (Biotech Scigenics Orbitek, India) at desired temperature of $30 \pm 1{ }^{\circ} \mathrm{C}$ and allowed it to shake for $1-48 \mathrm{~h}$ to attain equilibrium conditions. The samples were withdrawn at different time intervals to determine the change in absorbance. After completion of experiment, the collected samples were centrifuged (REMI Instruments Ltd, India) at
$10,000 \mathrm{rpm}$ for $10 \mathrm{~min}$ to separate the adsorbent from the dye solution. The absorbance was spectrophotometrically analyzed in the visible region $(\sim 490 \mathrm{~nm})$. The experiments were carried out in triplicates.

The amount of dye adsorbed at equilibrium ' $q_{\mathrm{e}}$ ' was calculated by the following equation,

$q_{\mathrm{e}}=\left(\frac{C_{0}-C_{\mathrm{e}}}{W}\right) \times V$

where $C_{0}$ and $C_{\mathrm{e}}(\mathrm{mg} / \mathrm{L})$ are the initial and equilibrium concentrations of dye solution, respectively. $V$ is the total volume of the solution (L) and $W$ is the weight (g) of SPS used for the study.

The percentage removal of dye from aqueous solution was calculated using the following equation:

$\%$ dye removal $=\left(\frac{C_{0}-C_{\mathrm{e}}}{C_{0}}\right) \times 100$

Effect of $\mathrm{pH}$ on adsorption

The effect of $\mathrm{pH}$ on the removal of RO-M2R dye by the adsorbent was studied at different $\mathrm{pH}(2-10)$. The $\mathrm{pH}$ of the solution was adjusted using small amounts of $0.1 \mathrm{~N} \mathrm{NaOH}$ or $0.1 \mathrm{~N} \mathrm{HCl}$. The experiments were carried out by agitating $100 \mathrm{~mL}$ of $100 \mathrm{mg} / \mathrm{L}$ initial dye concentration with a constant adsorbent mass of $0.2 \mathrm{~g} / 100 \mathrm{~mL}$ for an equilibrium time of $6 \mathrm{~h}$ at $120 \mathrm{rpm}$ and $30 \pm 1{ }^{\circ} \mathrm{C}$. The conical flask containing the dye solution without the adsorbent was maintained as control.

\section{Effect of contact time on adsorption}

The contact time influence in the range of $1-48 \mathrm{~h}$ was investigated with different initial dye concentrations (20, $50,100,150,200 \mathrm{mg} / \mathrm{L}$ ) at temperature $30 \pm 1{ }^{\circ} \mathrm{C}$ with constant adsorbent dosage of $0.2 \mathrm{~g} / 100 \mathrm{~mL}$.

Effect of initial adsorbent dosage and initial dye concentration on adsorption

The effect of initial adsorbent dosage on dye removal was investigated by changing the initial adsorbent dosage between 0.05 and $1.0 \mathrm{~g} / 100 \mathrm{~mL}$, while other experimental conditions such as initial dye concentration $(100 \mathrm{mg} / \mathrm{L})$, temperature $\left(30 \pm 1{ }^{\circ} \mathrm{C}\right)$ and $\mathrm{pH} 2$ were maintained for an equilibrium time of $6 \mathrm{~h}$. For the effect of initial dye concentration on the percentage removal of RO-M2R by SPS, the study was conducted at the experimental conditions of fixed adsorbent mass of $0.2 \mathrm{~g} / 100 \mathrm{~mL}$ with different initial dye concentrations (5-200 mg/L), pH 2 and temperature $\left(30 \pm 1{ }^{\circ} \mathrm{C}\right) \mathrm{kept}$ for an equilibrium time of $6 \mathrm{~h}$. 

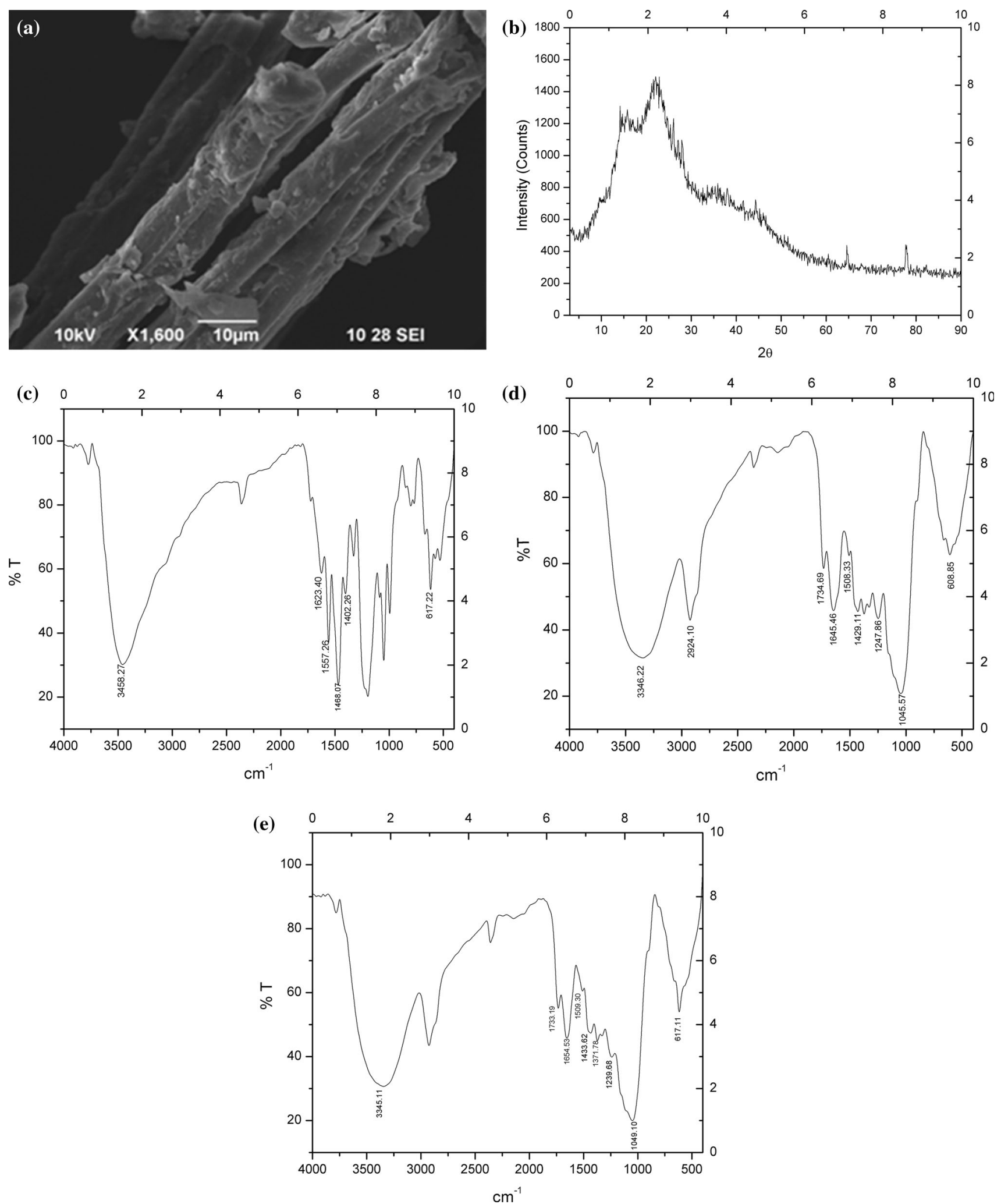

Fig. 1 Characterization of adsorbent. a SEM micrograph of SPS. b XRD pattern of SPS. $\mathbf{c}$ FTIR spectrum of RO-M2R. d FTIR spectrum of SPS. e FTIR spectrum: after adsorption of RO-M2R by SPS 


\section{Adsorption kinetics}

The adsorption kinetic study of RO-M2R dye on SPS was conducted with an initial dye concentration of $100 \mathrm{mg} / \mathrm{L}$ and $0.2 \mathrm{~g}$ of adsorbent material. The experiment was conducted at $\mathrm{pH} 2$ and temperature $30 \pm 1{ }^{\circ} \mathrm{C}$ for an equilibrium time of $6 \mathrm{~h}$. At various interval of time, samples were collected and centrifuged at 10,000 rpm for $10 \mathrm{~min}$ and absorbance was measured spectrophotometrically. The amount of adsorption at time $t, q_{t}(\mathrm{mg} / \mathrm{g})$ was calculated by the following equation:

$q_{t}=\frac{\left(C_{0}-C_{t}\right) V}{W}$

where $C_{0}$ and $C_{t}(\mathrm{mg} / \mathrm{L})$ are the concentrations of dye at initial and at time $t$, respectively, $V$ is the volume of the solution (L) and $W$ is the weight of adsorbent used in $(\mathrm{g})$.

SEM, XRD and FTIR analysis

In this study, scanning electron microscopy (SEM), powder X-ray diffraction (XRD) and Fourier transform infrared (FTIR) spectrophotometry analyses were performed in order to characterize the adsorbent SPS. The SEM used is JEOL 6390, Japan with a magnification of $1,600 \times$, XRD6000 Shimadzu, Japan and FTIR, ABB MB3000 with spectra recorded in the range of $400-4,000 \mathrm{~cm}^{-1}$.

\section{Results and discussion}

\section{Characterization of adsorbent}

Scanning electron microscopy analysis of SPS was carried out in order to study the morphological and surface characteristics of the adsorbent. Figure 1a shows the SEM micrograph of the adsorbent showing bundle-like structures with a heterogeneously textured surface. This surface consistency may aid the adsorption of the dye molecule over the SPS surface.

The X-ray diffraction analysis of SPS illustrated a highly crystalline nature indicated by the presence of broad main peak centered at $2 \theta$ of $22^{\circ}$, a characteristic peak of cellulosic material (Fig. 1b). The presence of the main peak ascertains the presence of highly organized crystalline cellulose content of SPS. The crystalline nature of the adsorbent may assist the dye adsorption over the material surface.

The FTIR is an effective tool to investigate various functional groups present in the prepared samples. In the case of pure RO-M2R, the obtained peaks around 3,458 and $1,623 \mathrm{~cm}^{-1}$ belong to $\mathrm{OH}$ stretching and aromatic $\mathrm{C}-\mathrm{C}$ stretching, respectively. The peaks around 1,557 and
$1,468 \mathrm{~cm}^{-1}$ resemble $\mathrm{C}-\mathrm{C}$ double-bond stretching vibrations and for alkyl acetals $\left(\mathrm{C}-\mathrm{H}\right.$ stretching) at $1,402 \mathrm{~cm}^{-1}$. The functional group $\mathrm{C}-\mathrm{N}$ stretching due to amines displayed at $1,196 \mathrm{~cm}^{-1}$. The peaks arrived at $617 \mathrm{~cm}^{-1}$ depicts $\mathrm{C}-\mathrm{Cl}$ stretching (Fig. 1c). The FTIR spectra of before and after adsorption of RO-M2R by SPS are shown in Fig. 1d, e. By comparing both the spectra, the shifting of peaks to higher wave number and the presence of amine group in the FTIR spectrum of after adsorption process confirms the presence of RO-M2R dye on the surface of the sample. All the observations are in good agreement with the literature (Jagwani et al. 2013).

Effect of $\mathrm{pH}$ and contact time on dye removal

$\mathrm{pH}$ is an important parameter for an adsorption experiment which directly has an impact on adsorption capacity of the adsorbent. The amount of dye adsorbed by adsorbent (mg/ g) decreased, when initial $\mathrm{pH}$ was increased from 2 to 10 (Fig. 2a). When the $\mathrm{pH}$ increased from 2 to 6 , the amount of dye adsorbed decreased from 9 to $3 \mathrm{mg} / \mathrm{g}$. With further increase in $\mathrm{pH}$ to 10 , there was no significant change in the adsorption of dye. A maximum adsorption of $9.36 \mathrm{mg} / \mathrm{g}$ was observed at $\mathrm{pH}$ 2. Similar adsorption behavior with respect to variation in $\mathrm{pH}$ was reported in the studies of Newcombe and Drikas (1997). High adsorption of anionic dye $\mathrm{RO}-\mathrm{M} 2 \mathrm{R}$ at low $\mathrm{pH}$ indicates that the system seems to be "below the point of zero charge". The studies of Giles et al. (1974) suggest that the overall surface of adsorbent becomes positively charged and the greater degree of adsorption observed may be due to hydrophobic interactions. The percentage of dye removal increased with increase in contact time (Fig. 2b). The adsorption percentage increased drastically at initial hours and it slowly attained an equilibrium value. The maximum percentage removal of RO-M2R dye was attained within $6 \mathrm{~h}$ and after that there was no significant increase in dye removal and it attained an equilibrium value.

Effect of initial adsorbent dosage and initial dye concentration

The results showed that the percentage removal of $\mathrm{RO}$ M2R dye increased from 18.05 to $51.81 \%$ with increase in initial adsorbent dosage from 0.05 to $1.0 \mathrm{~g} / 100 \mathrm{~mL}$ (Fig. 3a). The maximum dye removal of $51.81 \%$ was observed at an adsorbent dosage of $1.0 \mathrm{~g} / 100 \mathrm{~mL}$. Garg et al. $(2004 \mathrm{a}, \mathrm{b})$ reported that the increase in adsorbent dosage results in increased surface area and thereby increases the availability of adsorption sites for binding. While percentage adsorption increased, the unit adsorption $\left(q_{\mathrm{e}}\right)$ decreased from 36.11 to $5.18 \mathrm{mg} / \mathrm{g}$ with an increase in adsorption mass. Namasivayam et al. (1998) reported that 


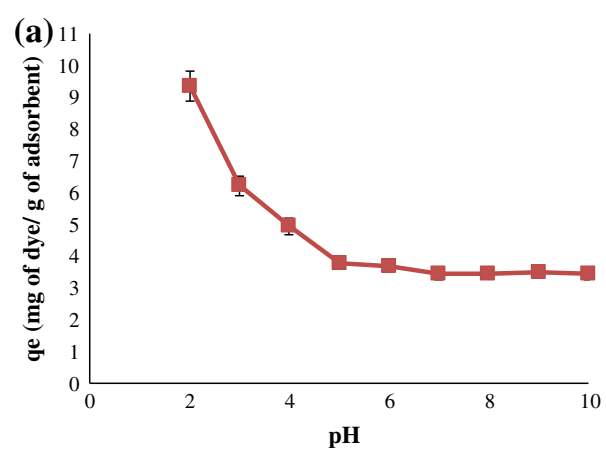

Fig. 2 a Influence of $\mathrm{pH}$ on RO-M2R dye removal onto adsorbent (SPS) from aqueous solution (temperature: $30 \pm 1{ }^{\circ} \mathrm{C}$, agitation speed: $120 \mathrm{rpm}, \mathrm{pH}: 2-10$, contact time: $6 \mathrm{~h}$ ), b Influence of contact (b)

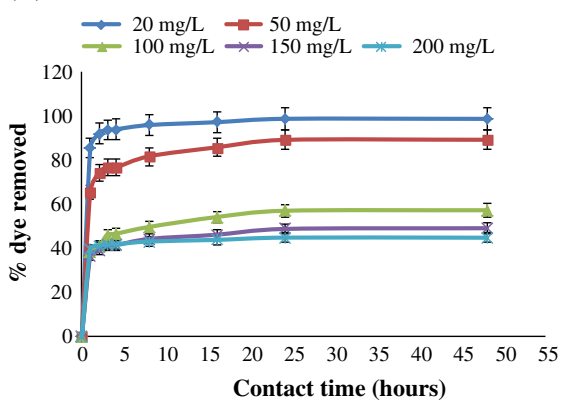

time on RO-M2R dye removal onto adsorbent from aqueous solution (temperature: $30 \pm 1{ }^{\circ} \mathrm{C}$, agitation speed: $120 \mathrm{rpm}, \mathrm{pH}: 2$ ) (a)

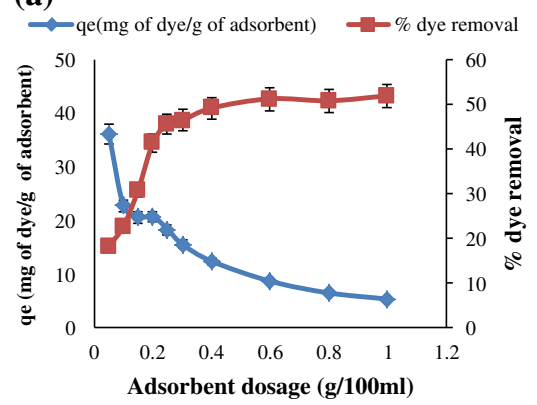

Fig. 3 a Influence of initial adsorbent dosage on RO-M2R dye removal onto adsorbent (SPS) from aqueous solution (temperature: $30 \pm 1{ }^{\circ} \mathrm{C}$, agitation speed: $120 \mathrm{rpm}, \mathrm{pH}: 2$ ), b Influence of initial

this effect may be due to overlapping or add up of adsorbent binding sites available to RO-M2R and it increases the diffusion path length of dye to reach the adsorption binding site.

This study revealed that the percentage removal of ROM2R decreased from 97.62 to $39.41 \%$ with increase in the initial concentration of dye (Fig. 3b). While the percentage removal dye decreased, the unit adsorption $\left(q_{\mathrm{e}}\right)$ increased from 2.44 to $39.41 \mathrm{mg} / \mathrm{g}$ with increase in the initial dye concentration. This may be attributed to the presence of higher residual dye concentration for higher initial dye concentration. It is evident from the studies of $\mathrm{Ju}$ et al. (2006) that the adsorption capacity for the RO-M2R increases with initial dye concentration because of the concentration gradient. It was also observed that the active sites on the adsorbent for dye removal may become saturated as the dye concentration increases.

\section{Adsorption isotherms}

The adsorption isotherm is of basic importance in the modeling of adsorption. Bello et al. (2010) reported that the adsorption isotherm expresses the distribution of dye (b)

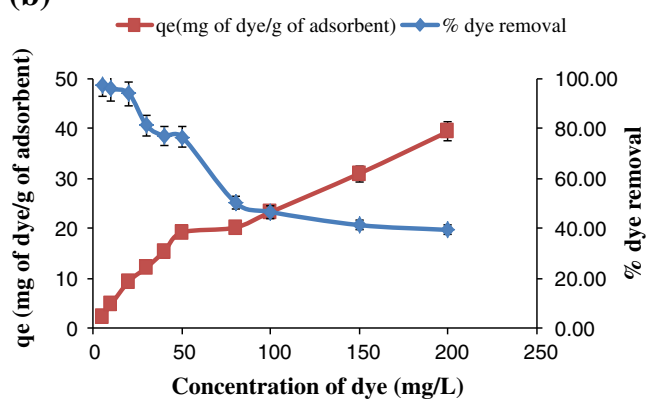

dye concentration on RO-M2R dye removal onto adsorbent from aqueous solution (temperature: $30 \pm 1{ }^{\circ} \mathrm{C}$, agitation speed: $120 \mathrm{rpm}$, $\mathrm{pH}: 2)$

between the liquid phase and the adsorbent phase, when the process reaches its equilibrium state. In order to quantify the adsorption affinity of SPS for RO-M2R and to find out the best model for the design of adsorption process, the adsorption equilibrium data should exactly fit into different isotherm models (Langmuir and Freundlich isotherm models).

The Freundlich isotherm assumes the multilayer adsorption and for the adsorption on heterogeneous surfaces and it is represented by an equation below,

$\log q_{\mathrm{e}}=\log K_{\mathrm{f}}+\frac{1}{n} \log C_{\mathrm{e}}$

where $q_{\mathrm{e}}$ is the amount of dye adsorbed per unit mass of adsorbent $(\mathrm{mg} / \mathrm{g}), C_{\mathrm{e}}$ is concentration of dye at equilibrium $(\mathrm{mg} / \mathrm{L}), K_{\mathrm{f}}$ roughly shows the adsorption capacity and $\frac{1}{n}$ represents the adsorption intensity. The coefficients $K_{\mathrm{f}}$ and $n$ can be estimated from intercept and slope in the graph of $\log q_{\mathrm{e}}$ vs $\log C_{\mathrm{e}}$ (Fig. 4a) and presented in Table 1. The linear plot for the graph of 20,50,100,150, $200 \mathrm{mg} / \mathrm{L}$ dye concentrations substantiates the applicability of the Freundlich isotherm model $\left(R^{2}>0.97\right)$. The $n$ value greater than 1 represents favorable adsorption condition. The 
Fig. 4 Adsorption isotherms. a Freundlich plot. b Langmuir plot

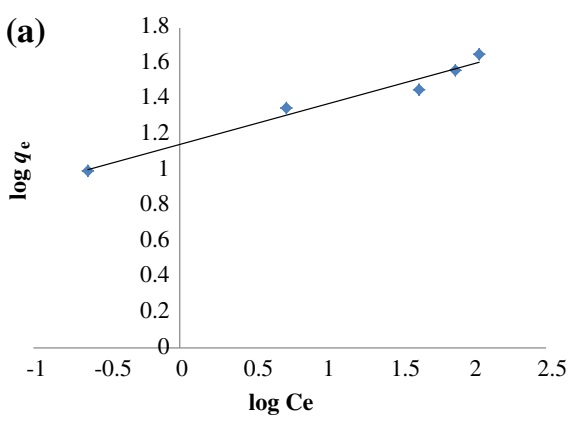

Table 1 Isotherms Constants

\begin{tabular}{|c|c|c|c|c|c|}
\hline \multicolumn{3}{|c|}{ Langmuir coefficients } & \multicolumn{3}{|c|}{ Freundlich coefficients } \\
\hline$K_{\mathrm{L}}(\mathrm{L} / \mathrm{mg})$ & $S_{\mathrm{m}}(\mathrm{mg} / \mathrm{g})$ & $R^{2}$ & $K_{\mathrm{f}}(\mathrm{mg} / \mathrm{g})$ & $n$ & $R^{2}$ \\
\hline 0.114 & 44.247 & 0.951 & 14.01 & 4.405 & 0.972 \\
\hline
\end{tabular}

results suggest that the SPS favorably adsorbs RO-M2R dye.

Weber and Chakravorti (1974) indicated that the energy term in the Langmuir equation varies as a function of the surface exposure. The adsorption of RO-M2R in the current study was analyzed using Langmuir adsorption model which is represented by the following equation (Inbaraj et al. 2002; Annadurai et al. 1999; Stephen et al. 1989; ElGeundi 1991; Lata et al. 2007),

$\frac{C_{\mathrm{e}}}{q_{\mathrm{e}}}=\frac{1}{K_{\mathrm{L}} S_{\mathrm{m}}}+\frac{C_{\mathrm{e}}}{S_{\mathrm{m}}}$

where $S_{\mathrm{m}}$ is the maximum amount of adsorption per unit mass of adsorbent $(\mathrm{mg} / \mathrm{g})$ resembles the complete monolayer surface coverage (Pavan et al. 2008), $C_{\mathrm{e}}$ represents the concentration of dye at equilibrium $(\mathrm{mg} / \mathrm{L}), K_{\mathrm{L}}$ represents the Langmuir constant (L/mg). Fytianos et al. (2000) reported that the Langmuir isotherm assumes uniform strategies of adsorption. $S_{\mathrm{m}}$ helps in the comparison of adsorption capacity. The coefficients $K_{\mathrm{L}}$ and $S_{\mathrm{m}}$ can be calculated from intercept and slope in the graph of $\log C_{\mathrm{e}} / q_{\mathrm{e}} \mathrm{vs} \log C_{\mathrm{e}}$ (Fig. 4b) and is presented in Table 1. The linear plot for the graph of 20 , $50,100,150$ and $200 \mathrm{mg} / \mathrm{L}$ dye concentrations substantiates the applicability of the Langmuir isotherm model $\left(R^{2}>0.95\right)$. The essential uniqueness of Langmuir isotherm can be expressed by a dimensionless constant separation factor for equilibrium parameter, $R_{\mathrm{L}}$ (Hall et al. 1966) which can be calculated as below,

$R_{\mathrm{L}}=\frac{1}{\left(1+K_{\mathrm{L}} C_{0}\right)}$

where $C_{0}$ is the initial concentration of dye $(\mathrm{mg} / \mathrm{L})$ and $K_{\mathrm{L}}$ is the Langmuir constant $(\mathrm{L} / \mathrm{mg})$. The values of $R_{\mathrm{L}}$ indicate the shape of the isotherm. The shape of the isotherm may be interpreted, when $R_{\mathrm{L}}>1$ as unfavorable, $R_{\mathrm{L}}=1$ as linear, $1>R_{\mathrm{L}}>0$ as favorable and $R_{\mathrm{L}}=0$ as irreversible adsorption. The magnitudes of $R_{\mathrm{L}}$ for the adsorption process studied at different initial dye concentrations ranged between 0 and 1, thus indicating a favorable adsorption process between SPS and RO-M2R dye.

Adsorption kinetic studies

To determine the potential rate-controlling steps involved in the mechanism of solute sorption onto the adsorbent, kinetic studies were carried out. Several kinetic models can be used to investigate the adsorption process. In this study, pseudo-first-order, pseudo-second-order and intra-particle diffusion models were employed to understand the dependency of time over the concentration distribution of the solute both in bulk solution and solid adsorbent phases.

The Lagergren's pseudo-first-order equation is generally expressed as (Yuh-Shan Ho 2004; Lata et al. 2008),

$\log \left(q_{\mathrm{e}}-q_{t}\right)=\log \left(q_{\mathrm{e}}\right)-\left(\frac{k_{1}}{2.303}\right) t$

where $q_{\mathrm{e}}$ and $q_{t}(\mathrm{mg} / \mathrm{g})$ are the amount of dye adsorbed per unit mass of adsorbent at equilibrium and at time $t$ (min), respectively, $k_{1}$ is the rate constant of pseudo-first-order kinetics $(1 / \mathrm{min})$. The linear plot of $\log \left(q_{\mathrm{e}}-q_{t}\right)$ as a function of adsorption time $(t)$ is shown in Fig. 5a. The values of $k_{1}$ and $q_{\mathrm{e}}$ can be calculated from the slope and intercept of the plot, respectively, are shown in Table 2 .

Kinetic data of the present study were employed in the pseudo-second-order rate expression (Poots et al. 1978),

$\frac{t}{q_{t}}=\left(\frac{1}{k_{2} q_{\mathrm{e}}^{2}}\right)+\left(\frac{t}{q_{\mathrm{e}}}\right)$

where $k_{2}$ is the rate constant of pseudo-second-order kinetics $(\mathrm{g} / \mathrm{mg} / \mathrm{min})$. The linear plot of $\left(t / q_{t}\right)$ as function of time $(t)$ is shown in Fig. 5b. The values of $q_{\mathrm{e}}$ and $k_{2}$ can be calculated from the slope and intercept of the plot, respectively, are shown in Table 2.

Singh and Rawat (1994) reported that the adsorption process includes the transport of adsorbate molecules from 
Fig. 5 Adsorption Kinetics. a Lagergren's first-order plot. b Pseudo-second-order plot. c Intra-particle diffusion model for adsorption
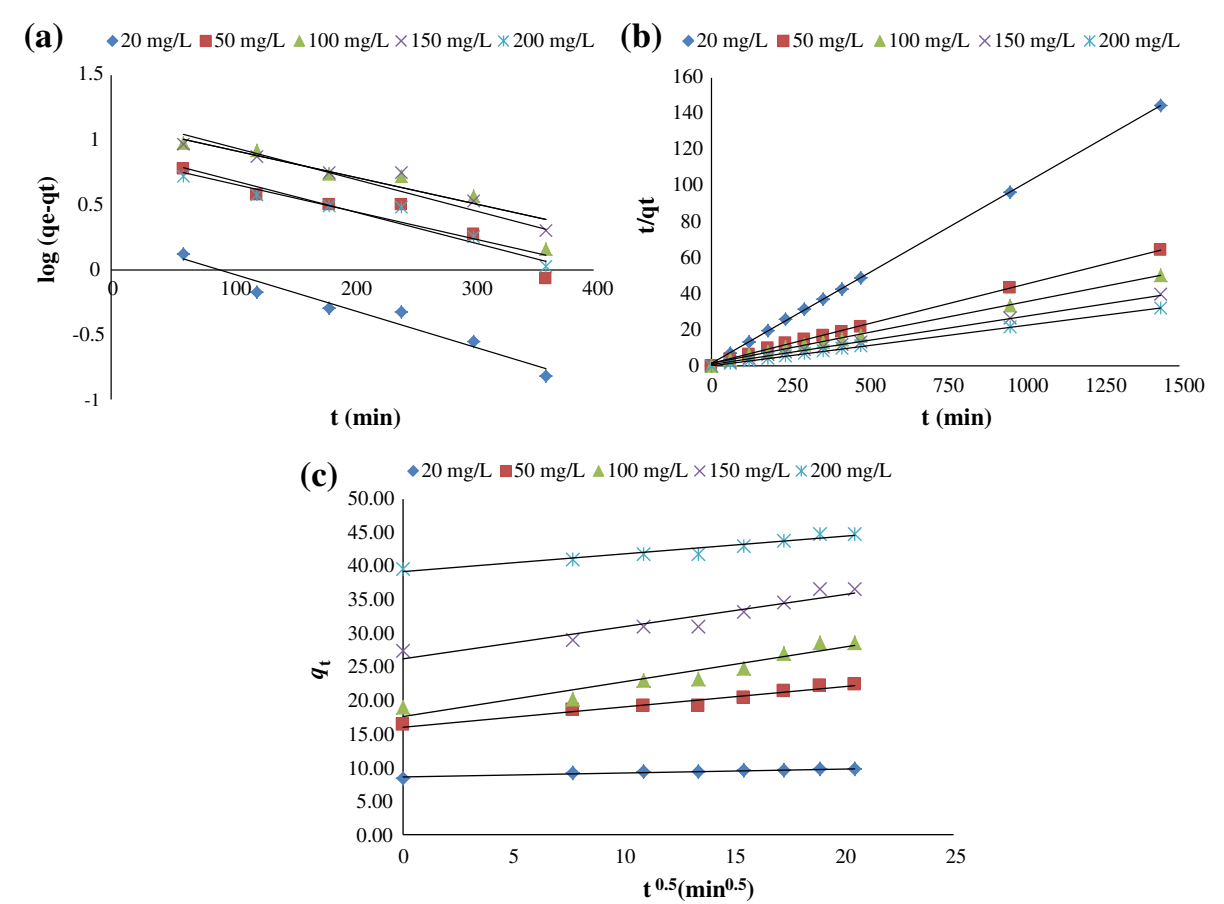

Table 2 Linearized kinetic coefficients for the dye sorption onto SPS

\begin{tabular}{|c|c|c|c|c|c|c|c|c|c|c|}
\hline \multirow{2}{*}{$\begin{array}{l}\text { Dye } \\
(\mathrm{mg} / \mathrm{L})\end{array}$} & \multirow{2}{*}{$\begin{array}{l}\text { Theoretical }\left(\mathrm{q}_{\mathrm{e}}\right) \\
(\mathrm{mg} / \mathrm{g})\end{array}$} & \multicolumn{3}{|c|}{ Pseudo-first order } & \multicolumn{3}{|c|}{ Pseudo-second order } & \multicolumn{3}{|c|}{ Intra-particle diffusion } \\
\hline & & $\left(q_{\mathrm{e}}\right)_{\mathrm{cal}}$ & $K_{1}$ & $R^{2}$ & $\left(\mathrm{q}_{\mathrm{e}}\right)_{\mathrm{cal}}$ & $K_{1}$ & $R^{2}$ & $K_{\mathrm{i}}$ & $\mathrm{C}$ & $R^{2}$ \\
\hline 20 & 9.88 & 1.759 & 0.384 & 0.9483 & 9.921 & 0.017 & 1.0000 & 0.032 & 8.909 & 0.8049 \\
\hline 50 & 22.31 & 8.602 & 0.337 & 0.8867 & 22.573 & 0.002 & 0.9996 & 0.157 & 17.280 & 0.9039 \\
\hline 100 & 28.51 & 15.646 & 0.341 & 0.8752 & 29.070 & 0.001 & 0.9992 & 0.274 & 19.598 & 0.9088 \\
\hline 150 & 36.57 & 13.530 & 0.288 & 0.9228 & 37.037 & 0.001 & 0.9995 & 0.264 & 27.849 & 0.9321 \\
\hline 200 & 44.82 & 7.434 & 0.296 & 0.9205 & 45.045 & 0.003 & 0.9999 & 0.145 & 40.080 & 0.9302 \\
\hline
\end{tabular}

bulk solution to the interior surface of the pores. The applicability of intra-particle diffusion was investigated using intra-particle diffusion model (Ozcan and Ozcan 2005; Weber and Morris 1963).

$q_{t}=k_{i} t^{0.5}+C$

where $q_{\mathrm{t}}$ is the unit adsorption of dye $(\mathrm{mg} / \mathrm{g})$ at time, $t$ (min), $k_{\mathrm{i}}$ is the intra-particle diffusion rate constant $(\mathrm{mg} /$ g.min ${ }^{0.5}$ ) and $C$ represents boundary layer effect which indicates that, greater the value of $\mathrm{C}$ larger the boundary layer thickness (Lee et al. 1999). The linear plot of $q_{\mathrm{t}}$ versus $t^{0.5}$ of Eq. 9 is shown in Fig. 5c. The values of $k_{\mathrm{i}}$ and $C$ can be calculated from the slope and intercept of the plot, respectively, are shown in Table 2 .

\section{Conclusion}

In this study, the maximum dye removal was observed at the experimental conditions of $\mathrm{pH} \mathrm{2,} \mathrm{equilibrium} \mathrm{time}$
$6 \mathrm{~h}$, temperature $30 \pm 1{ }^{\circ} \mathrm{C}$ and an adsorbent dose of $0.2 \mathrm{~g} / 100 \mathrm{~mL}$. The adsorption capacity was found to change with adsorbent dosage, initial dye concentration and $\mathrm{pH}$. Adsorption kinetic studies showed that the rate of adsorption obeyed pseudo-second-order kinetics model with good correlation. Equilibrium data followed both Langmuir and Freundlich isotherm models well (Lee et al. 1999; Ong et al. 2007; Malik 2003). The fitness of data with Langmuir model confirms the monolayer coverage of the adsorbate (RO-M2R) onto the outer surface of the adsorbent (SPS). SPS is economically cheap, and hence, regeneration is not necessary. Strychnos potatorum Linn trees are widely available in India, and its seeds are available at zero cost or negligible price. The data provided in the study may be useful in designing and fabricating a economically feasible treatment process using batch or continuos stirred tank reactors for the removal of $\mathrm{RO}-\mathrm{M} 2 \mathrm{R}$ from industrial effluents by adsorption on SPS. 
Acknowledgments The authors would like to express their gratitude to the Department of Biotechnology, Bannari Amman Institute of Technology, Sathyamangalam, India for providing infrastructural support to carry out this research work and to Karunya University, Coimbatore, India for lending support in SEM and XRD analysis.

\section{References}

Annadurai G, Chellapandian M, Krishnan MRV (1999) Adsorption of reactive dye on chitin. Environ Monit Assess 59:111-119

Bello OS, Adelaide OM, Hammed MA, Popoola OAM (2010) Kinetic and Equilibrium studies of methylene blue removal from aqueous solution by adsorption on treated sawdust. Maced $\mathrm{J}$ Chem Chem Eng 29:77-85

El-Geundi MS (1991) Colour removal from textile effluents by adsorption techniques. Water Res 25:271-273

Fytianos K, Voudrias E, Kokkalis E (2000) Sorption-desorption behavior of 2, 4-dichlorophenol by marine sediments. Chemosphere 40:3-6

Garg VK, Amita M, Kumar R, Gupta R (2004a) Basic dye (methylene blue) removal from simulated wastewater by adsorption using Indian Rosewood sawdust: a timber industry waste. Dyes Pigments 63:243-250

Garg VK, Kumar R, Gupta R (2004b) Removal of malachite green dye from aqueous solution by adsorption using agro-industry waste: a case study of Prosopis cineraria. Dyes Pigments 62:1-10

Giles C, Huitson A, Smith D (1974) A general treatment and classification of the solute adsorption isotherms. J Colloid Interface Sci 47:755-765

Gregory AR, Elliot S, Kluge P (1991) Ames testing of direct black 3B parallel carcinogenecity. J Appl Toxicol 1:308-313

Hall KR, Eagleton LC, Acrivos A, Vermeulen T (1966) Pore and solid diffusion kinetics in fixed bed adsorption under constant pattern conditions. Ind Eng Chem Fund 5:212-228

Inbaraj BS, Selvarani K, Sulochana N (2002) Evaluation of carbonaceous sorbent prepared from pearl millet husk for its removal of basic dye. J Sci Ind Res 61:971-978

Jagwani JS, Sharma MC, Lakshmi B (2013) COD reduction and biodegradation of textile dye reactive orange M2R by newly isolated bacterial consortium VSS. Int $\mathrm{J}$ Environ Ecol Fam Urban Stud 3(2):69-78. ISSN 2250-0065

Ju DJ, Byun IG, Lee CH, An GH, Park TJ (2006) Biosorption characteristics of reactive dye onto dried activated sludge. Water Pract Technol 1(3). doi:10.2166/WPT.2006.066

Khan A, Tabrez Singh V, Kumar D (2004) Removal of some basic dyes from artificial textile wastewater by adsorption on Akash Kinari Coal. J Sci Ind Res 63:355-364

Kirtikar KR, Basu BD (1933) Indian medicinal plants, vol 3. Basu LM Publications, Allahabad, p 1647

Kirtikar KR, Basu BD (2000) Illustrated Indian Medicinal Plants, vol 7. Sir Satguru's Publications, New Delhi, India, p 2271

Lata H, Garg VK, Gupta RK (2007) Removal of a basic dye from aqueous solution by adsorption using Parthenium hysterophorus: an agricultural waste. Dyes Pigments 74:653-658
Lata H, Garg VK, Gupta RK (2008) Adsorptive removal of basic dye by chemically activated Parthenium biomass: equilibrium and kinetic modeling. Desalination 219:250-261

Lee CK, Low KS, Gan PY (1999) Removal of some organic dyes by acid treated spent bleaching earth. Environ Technol 20:99-104

Malik PK (2003) Use of activated carbons prepared from sawdust and rice-husk for adsorption of acid dyes: a case study of Acid Yellow 36. Dyes Pigments 56:239-249

Namasivayam C, Prabha D, Kumutha M (1998) Removal of direct red and acid brilliant blue by adsorption onto banana pith. Bioresour Technol 64:77-79

Namasivayam C, Kumar MD, Selvi K, Ashruffunissa BR, Vanathi T, Yamuna RT (2001) 'Waste' coir pith—a potential biomass for the treatment of dyeing waste water. Biomass Bioenergy 21:477-483

Newcombe G, Drikas M (1997) Adsorption of NOM activated carbon: electro-static and non-electrostatic effects. Carbon 35:1239-1250

Ong ST, Lee CK, Zainal Z (2007) Removal of basic and reactive dyes using ethylenediamine modified rice hull. Bioresour Technol 98:2792-2799

Ozacar M, Sengil IA (2003) Adsorption of reactive dyes on calcined alunite from aqueous solution. J Hazard Mater B 98:211-224

Ozcan A, Ozcan AS (2005) Adsorption of Acid Red 57 from aqueous solutions onto surfactant-modified sepiolite. J Hazard Mater 125:252-259

Pavan FA, Mazzocato AC, Gushikem Y (2008) Removal of methylene blue dye from aqueous solutions by adsorption using yellow passion fruit peel as adsorbent. Bioresour Technol 99:3162-3165

Pollard SJT, Fowler GD, Sollars CJ, Perry R (1992) Low cost adsorbents for water and waste water treatment: a review. Sci Total Environ 116:31-52

Poots VJP, McKay G, Healy JJ (1978) Pseudo-Second Order Model for Sorption Processes. J Water Pollut Control Fed 50:926-935

Ramakrishna KR, Viraraghavan T (1997) Dye removal using low cost adsorbents. Water Sci Technol 36:189-196

Sid Kalal H, Hoveidi H, Thagiof M, Pakizevand N, Almasian MR, Firoozzare MA (2012) Pre-concentration and determination of platinum (IV) in water samples using chelating resin by inductively coupled plasma atomic emission spectroscopy (ICP-AES). Int J Environ Res 6(3):739-750

Singh BK, Rawat NS (1994) Comparative sorption kinetic studies of toxic phenols on fly ash and impregnated fly ash. J Chem Technol Biotechonol 61:57-65

Sivaraj R, Namasivayam C, Kadirvelu K (2000) Orange peel as an adsorbent in the removal of acid violet 17 (acid dye) from aqueous solutions. Waste Manag 21:105-110

Stephen JA, McKay G, Khader KYH (1989) Equilibrium adsorption isotherms for basic dyes onto lignite. J Chem Technol Biot 45:29-32

Weber TW, Chakravorti RK (1974) Pore and solid diffusion models for fixed-bed adsorbers. AIChE J 20:228-238

Weber WJ, Morris JC (1963) Kinetics of adsorption on carbon from solution. J Sanit Eng Div Am Soc Civ Eng 89:31-60

Yuh-Shan Ho (2004) Citation review of Lagergren kinetic rate equation on adsorption reactions. Scientometrics 59:171-177 